\title{
ARTIGOS
}

\section{CATALOGAÇÃO E SISTEMATIZAÇÃO DE ACAMPAMENTOS PLANEJADOS - FUTURA PLATAFORMA INFRASHELTER}

\section{CATALOGING AND SYSTEMATIZING PLANNED CAMPS - FUTURE INFRASHELTER PLATFORM}

\author{
THAIS NOLIO SANTA CRUZ | UFSC \\ LISIANE ILHA LIBRELOTTO, Dra. | UFSC \\ LUANA TORALLES CARBONARI, Dra. | UFSC \\ NADIELI DE ARAUJO | UFSC
}

\begin{abstract}
RESUMO
Os acampamentos planejados são instalações que pertencem à categoria de abrigos transitórios e visam atender a população vítima de desastres naturais e/ou conflitos. Este artigo propõe a elaboração de um sistema de catalogação de materiais, estruturas e tecnologias de acampamentos temporários planejados. O catálogo baseou-se em indicadores para escolha dos locais de implantação e da estrutura dos acampamentos. Elaborou-se uma lista com os acampamentos que se relacionam às principais emergências ocorridas no Brasil e no mundo. Como critério de seleção, adotou-se um intervalo temporal de onze anos. Dentre os acampamentos selecionados, utilizou-se como exemplo da proposta de sistematização, o acampamento de Zaatari, na Jordânia. Além disso, explicou-se a maneira que os catálogos serão inicialmente publicados no Portal Virtuhab e realizou-se algumas sugestões para a elaboração da futura plataforma denominada Infrashelter. A catalogação das soluções adotadas pode auxiliar no desenvolvimento e implementação de novos acampamentos planejados.
\end{abstract}

PALAVRAS-CHAVE: Abrigos emergenciais; Acampamentos temporários planejados; Sustentabilidade

\begin{abstract}
Planned camps are installations that belong to the category of transitional shelters and aim to assist population victims of natural disasters and/or conflicts. This paper proposes the development of a cataloging system for materials, structures and technologies of planned temporary camps. The catalog was based on indicators for selecting implantation sites and structure of camps. A list of planned camps that are related to the main emergencies in Brazil and worldwide was established. As a selection criterion, a time interval of 11 years was adopted. Among the selected camps, the Zaatari Camp in Jordan was used to exemplificate the systematization carried out. In addition, the way that the catalogs will initially be published on the Virtuhab Portal was explained and some suggestions were made for the future platform structure, called Infrashelter. The cataloging of the adopted solutions can assist in the development and implementation of new planned camps.
\end{abstract}

KEYWORDS: Emergency shelters; Temporary planned camps; Sustainability 


\section{INTRODUÇÃO}

A ajuda humanitária tem por diretriz preservar vidas e garantir a integridade, subsistência e as necessidades das populações sujeitas a desastres, conflitos sociais ou até uma combinação de ambos. O auxílio depende de diversos fatores, sejam ambientais, econômicos ou governamentais (SPHERE ASSOCIATION, 2018; SHELTER CENTRE, 2010).

Um desastre é uma consequência de acontecimentos inesperados em algum ambiente, que pode causar avarias materiais, humanas ou físicas e perdas econômicas e sociais. A origem do desastre pode apresentar influência humana, ser um fenômeno natural, ou uma junção de ambas (DE CASTRO, 2009). Os desastres naturais se relacionam a fenômenos climáticos e geofísicos, como terremotos, tufões, furacões, deslizamentos de terra, erupção de vulcões, dentre outros. Estes podem ser agravados pela influência humana aliado à característica socioespacial do local, à rápida urbanização e ao crescimento desordenado das cidades. Assim, a vulnerabilidade ambiental aumenta, intensificando eventos naturais como chuvas volumosas, inundações e tornados (ALCÁNTARA-AYALA, 2002; TOMINAGA; SANTORO; AMARAL, 2009).

De acordo com a ACNUR-BRASIL (c2021), em 2019, cerca de 79,5 milhões de pessoas foram deslocadas de seus lugares de origem em função de conflitos sociais e/ou armados e perseguições, que se relacionam a raça, religião, nacionalidade, política, entre outros. Dentre os principais países de origem das migrações forçadas se destacam a Venezuela, o Afeganistão, o Sudão do Sul, Mianmar e a Síria. Este último responde pelo maior número de refugiados do mundo, cerca de 824.400 pessoas, abrigadas principalmente na Turquia, Jordânia, Líbano e Egito. $O$ destino dos refugiados pode envolver locais no mesmo país de origem ou destinos internacionais. A tendência de deslocamento é em direção aos países vizinhos. O Paquistão recebe refugiados do Afeganistão, assim como a Uganda acolhe pessoas do Sudão do Sul, que totalizavam $68 \%$ da população do país em 2016. Ainda, é possível observar o retorno dos refugiados aos locais de origem, como o caso de pessoas que retornam ao Afeganistão. Na América do Sul, de acordo Carbonari (2021), os refugiados venezuelanos buscam abrigo nos países vizinhos, como no caso do Brasil, onde se concentram na cidade de Boa Vista, capital do estado de Roraima.

Assim, é imprescindível oferecer atendimento humanitário às vítimas de desastres e/ou conflitos, identificando as ameaças e a vulnerabilidade dos lugares. A partir disso é possível prever a incidência dos desastres e tomar atitudes de resposta, que envolve profissionais de saúde, bombeiros e, quando necessário, a implementação de abrigos temporários (LEMES; REZENDE, 2017).

Este artigo apresenta como tema os acampamentos temporários planejados, que são instalações que visam atender à população envolvida em desastres e conflitos. Mais especificamente, trata-se da elaboração de um sistema de catalogação dessas instalações, baseado na estrutura de indicadores estabelecida por diversos autores, em especial Carbonari (2021). Em linhas gerais, o artigo abordará a conceituação geral dos acampamentos planejados, estrutura necessária para seu funcionamento, algumas propostas de estabelecimento de indicadores e modelos de tomada de decisão em acampamentos, uma lista preliminar de acampamentos planejados internacionais e nacionais já utilizados, e a explicação da disponibilização dos catálogos, na plataforma Infrashelter e no Portal Virtuhab (https://portalvirtuhab.paginas.ufsc.br/).

\section{MÉTODO, ETAPAS E TÉCNICAS DE PESQUISA}

A pesquisa compreende a criação de um catálogo para sistematizar as informações de acampamentos planejados. Para tanto, realizou-se uma revisão bibliográfica, utilizando as principais publicações na área de estudo, a saber: Patterns of sheltering and housing in american disasters de Quarantelli (1991); Administração para Abrigos Temporários de SEDEC-RJ (2006); Transitional settlement: displaced populations de Corsellis e Vitale (2005); The Sphere Handbook: Humanitarian Charter and Minimum Standards in Humanitarian Response da Sphere Association (2018) e Indicadores e diretrizes para a seleção e projeto de abrigos temporários móveis pós-desastres naturais de Carbonari e Librelotto (2018). Assim, com base nesses autores, determinou-se os conceitos relacionados às instalações de ajuda humanitária, como abrigos e acampamentos planejados. Ainda, selecionou-se diversos indicadores apontados como importantes na escolha dos locais de implantação dos acampamentos planejados e da estrutura dos abrigos com base em Sphere Association (2018), Carbonari (2021), SEDEC-RJ (2006) e Nappi e Souza (2014). Com base nestes critérios, elaborou-se a estrutura do catálogo, selecionando os principais aspectos que compõem os indicadores, além de sistematizar informações básicas a respeito dos eventos ocorridos e da população acolhida.

Ademais, realizou-se uma revisão e seleção dos principais desastres e casos de acolhimento de refugiados que utilizaram abrigos ou acampamentos planejados, no Brasil e no mundo. Como critério de seleção se adotou um 
limite temporal, entre 2010-2021. Ainda, demonstrou-se a aplicação do catálogo para um dos casos selecionados anteriormente, o acampamento de Zaatari, na Jordânia. A sistematização dos dados coletados, ou seja, as fichas de catalogação dos casos selecionados serão disponibilizadas inicialmente no Portal Virtuhab (https://portalvirtuhab.paginas.ufsc.br/) e posteriormente em uma plataforma online, denominada de Infrashelter.

\section{REFERENCIAL TEÓRICO}

\subsection{Conceituação}

As instalações oferecidas pelas organizações humanitárias apresentam diversas classificações, de acordo com o objetivo. Dentre estas, é imprescindível destacar os abrigos, particularmente os temporários, e os acampamentos planejados. Ainda, deve-se entender a diferença entre abrigos e habitações. Muitos termos são utilizados como sinônimos ou derivações, entre eles: abrigos emergenciais, transitórios e temporários, arquitetura emergencial, alojamentos, cidades temporárias, acampamentos emergenciais e planejados, entre outros. Pouco a pouco, tais termos vêm ganhando definições distintas e maior uniformidade em suas aplicações (CARBONARI; LIBRELOTTO, 2018; QUARANTELLI, 1991).

Para Corsellis e Vitale (2005) os abrigos se caracterizam como ambientes cobertos que proporcionam um local protegido, privativo e digno para as pessoas. O sistema de funcionamento se baseia na disponibilização de um local seguro e de distribuição de Non-food items-NFI, entretanto nem todas as definições corroboram esta. De acordo com a SEDEC-RJ (2006) há dois tipos de abrigos: fixos e móveis. Os fixos contam com instituições que atendem à população desabrigada, podendo ser pública ou privada. Já os móveis, baseiam-se em instalações que atuam em um determinado período, sendo que podem ser estruturas fixas, como ginásios, escolas, hotéis, ou móveis, como barracas alocadas em campos de futebol, quadras, terrenos escolhidos, entre outros. Ainda, segundo (CORSELLIS; VITALE, 2005) há os abrigos transitórios, que garantem as vantagens de um abrigo durante um período de tempo entre a ocorrência de um conflito, o desastre natural e a obtenção de soluções mais duradouras. Mais especificamente, os abrigos transitórios (transitional settlement) se classificam em seis tipos, divididos em soluções dispersas e agrupadas. Dentre as soluções agrupadas se localizam os acampamentos planejados, que se caracterizam pela escolha de um local que apresenta a infraestrutura e os serviços necessários.

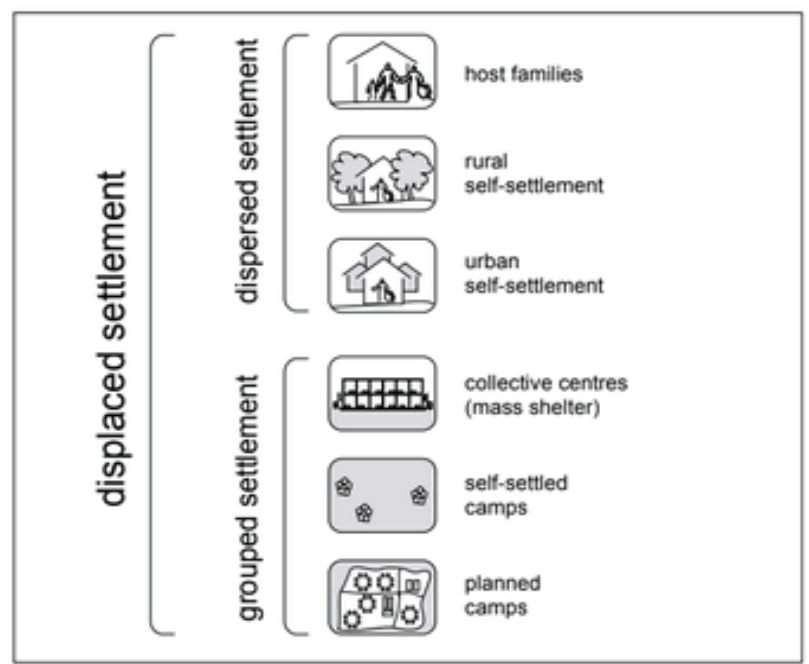

Figura 1 - As seis opções de abrigos temporários. Fonte: Corsellis e Vitale (2005)

Ainda, para Quarantelli (1991) há quatro tipologias que consideram diferenciações entre abrigos e habitações: Abrigos emergenciais, abrigos temporários, habitação temporária e habitação permanente. As habitações se caracterizam por apresentar a retomada das atividades rotineiras no local, e costumam se estender por um período de tempo maior, entre meses e anos. Nos abrigos, por outra parte, não há a tentativa de estabelecer alguma rotina no lugar, sendo o objetivo principal o retorno dos desabrigados a suas respectivas residências. Os abrigos emergenciais envolvem vítimas acolhidas em suas próprias casas ou em outros lugares durante o período da emergência, que pode durar horas ou até dias. Pela sua curta duração, as condições aceitas nem sempre são as ideais se comparadas a outros contextos. Geralmente são usados ambientes como igrejas, escolas e estádios. Já os abrigos temporários envolvem o alojamento de pessoas além do momento de emergência, necessitando de mais planejamento, comparado ao anterior, tal como a administração da alimentação à população. Em todas estas definições o abrigo compreende uma série de instalações para triagem, depósito, assistência médica e social e espaços para realização de atividades rotineiras como comer, dormir, estudar, recrear ou trabalhar, nem sempre se reportando somente a unidades privativas, mas a instalações comunitárias.

Assim, para o correto funcionamento dessas instalações, deve-se prever uma adaptação adequada ao contexto vigente, seja em aspectos físicos, culturais, econômicos ou políticos. As soluções devem envolver aspectos como a localização geográfica, interferência climática, disponibilidade de recursos, acesso a materiais de construção adequados, hábitos e práticas culturais locais, entre outros (UNHCR, 2019a, 2021a). 


\subsection{Implantação e estrutura de acampamentos temporários planejados}

Para o bom funcionamento dos acampamentos temporários planejados, a escolha do local de implantação apresenta grande importância, uma vez que há diversos critérios a serem adotados para garantir a segurança e o bem-estar dos residentes (CARBONARI; LIBRELOTTO, 2018; NAPPI; SOUZA, 2014). Para tanto, deve-se considerar questões de segurança e conforto ambiental da região. Ademais, é necessário atentar às características físicas do terreno, como a área necessária, aspectos geofísicos e possíveis áreas de subsistência. Outro ponto destacável se relaciona à localização dos acampamentos, sua interferência em relação ao acesso a infraestruturas básicas hidro sanitárias, elétricas e de transporte. Além disso, deve-se ressaltar a influência da acessibilidade, em termos de acesso às instalações, as possíveis rotas de emergência e escape necessárias e a acessibilidade universal.

Em concordância com Alshawawreh et al. (2020), Sphere Association (2018) e UNHCR (2019a) para garantir a proteção, a dignidade e a privacidade das vítimas, faz-se necessário um correto planejamento dos abrigos, levando em consideração diversos critérios. Entre estes, destacam-se a estrutura, materialidade e dimensões, assim como a inserção destes no contexto vigente e sua relação com a cultura e comunidade local, buscando sempre abrigos mais sustentáveis. Os abrigos devem suprir as necessidades dos residentes e deve-se priorizar o uso de materiais locais e sustentáveis, respeitando as práticas e costumes locais. Logo, abrigos inadequados podem causar diversos problemas com a população.

Portanto, nota-se a importância de considerar diversos critérios para a implantação de acampamentos e para adequação dos abrigos buscando o acolhimento das vítimas de conflitos e/ou desastres. Assim, é possível analisar os principais indicadores de locais de implantação de acampamentos planejados baseando-se em Carbonari (2021), Nappi e Souza (2014) e pela Sphere Association (2018), conforme o Quadro 1 e os principais indicadores dos abrigos usados como referência, fundamentado em Carbonari (2021), Sphere Association (2018) e SEDEC-RJ (2006), conforme o Quadro 2.

\begin{tabular}{|l|}
\hline INDICADORES DE IMPLANTAÇÃO DE ACAMPAMENTOS PLANEJADOS \\
\hline Segurança \\
\hline O local deve possibilitar o controle de acesso de pessoas e veículos, \\
além de estar distante de regiões de conflitos e vetores de transmis- \\
são de doenças. Ainda, deve estar em área não inundável, sem ventos \\
fortes e distante de áreas de risco e de preservação ambiental. A área \\
deve ser bem iluminada, permitindo a visibilidade dos acessos e saí- \\
das. Deve-se considerar a segurança das pessoas, principalmente das \\
crianças. Os acampamentos devem proporcionar um acesso seguro \\
a serviços essenciais em um período de tempo e distância aceitável. \\
\hline
\end{tabular}

\section{Infraestrutura Urbana}

O local deve ter acesso a tratamento ou coleta de esgoto, além de coleta de lixo, acesso a energia elétrica e abastecimento de água. Além de disponibilizar fontes de alimentação e instalações sociais, de saúde e para animais domésticos. Ademais, o local deve ser de fácil acesso a sistema de transporte de diferentes modais.

\section{Localização}

Deve-se considerar o acesso a serviços básicos como educação, saúde, apoio a atividades de subsistência. Ainda, é importante levar em conta a distância entre o local e o centro da cidade, os portos marítimos e rodoviárias, além das condições das estradas locais e próximas ao acampamento. Também, a distância a ser percorrida pela população desabrigada e o tempo máximo de chegada de suprimentos. Deve-se considerar as condições das estradas locais e a proximidade do acampamento em relação a terminais de transporte que forneçam ajuda e outros bens.

\section{Características Físicas}

Em relação a área, deve-se considerar as medidas mínimas estabelecidas nos documentos oficiais e possibilitar expansão. Deve-se evitar locais com solo arenoso e com lençol freático ou que possam ser afetados por enchentes. A declividade do terreno deve ser de 1\%-6\%. Ainda, há a possibilidade de criação de hortas comunitárias, agricultura e criação de animais, gerando oportunidades de emprego.

\section{Meio Ambiente}

O local deve oferecer conforto térmico e acústico, ventilação, iluminação natural e proteção à população abrigada. A vegetação do local deve ser preservada. Deve-se aproveitar a ventilação natural, evitando a exposição solar intensa. Ainda, impactos negativos no ambiente devem ser evitados, para tanto deve-se considerar para a seleção do local uma avaliação de impacto ambiental, levando em conta a exposição a riscos climáticos. Ainda, deve-se prever possíveis mudanças climáticas no local.

\section{Acessibilidade}

O local deve oferecer estradas, caminhos e acesso seguros. O acesso ao local deve ser feito por pessoas e veículos, verificando como é feito o acesso, além das condições das ruas e a segurança dos caminhos. Ainda, devem haver áreas de fácil acesso e evacuação. Ainda, deve-se considerar as necessidades das pessoas com deficiência de mobilidade. A Norma Brasileira NBR 9050 deve ser cumprida.

\section{Aspectos Econômicos}

Torna-se importante levar em conta o custo da implantação, sendo que os serviços devem ser de custo acessível, e deve-se permitir outros usos no local. Assim, deve-se apresentar uma estratégia consensual de prestação de serviços e de manutenção a um custo acessível, verificando o proprietário do local e diminuindo custos. Além disso, deve-se evitar a subutilização do local.

Quadro 1 - Indicadores de implantação de acampamentos planejados

Fonte: elaborado pelos autores com base em Carbonari (2021), Nappi; Souza (2014) e Sphere Association (2018)

\begin{tabular}{|l|}
\hline INDICADORES DE ESTRUTURAS DOS ABRIGOS \\
\hline Características Físicas e Espaciais \\
\hline Os abrigos devem possuir um espaço coberto com finalidade de \\
proteger as pessoas contra intempéries climáticas, oferecendo con- \\
dições propícias de temperatura, segurança e privacidade. A área \\
do acampamento deve ser de no mínimo $45 \mathrm{~m}^{2}$ ( $30 \mathrm{~m}^{2}$ de abrigo e 15 \\
m² para áreas de cocção e hortas). No centro dos acampamentos, ou $^{2}$ seja, fora da área dos abrigos, deve-se priorizar instalar adminis- \\
trações, atendimento à saúde, alimentação e educação, depósito, \\
entre outros.O acesso de pedestres e veículos deve ser separado. \\
Já os abrigos devem possuir um espaço coberto com finalidade \\
de proteger as pessoas contra intempéries climáticas, sendo a \\
área mínima de $3,5 m^{2}$ por pessoa e $10 m^{2}$ por família. Em situações \\
emergenciais, deve-se construir primeiramente uma cobertura para \\
os abrigos, dando sequência com as paredes, portas e janelas. \\
\hline
\end{tabular}




\section{Instalações de Apoio e Serviço}

Entre os principais serviços oferecidos se encontram: a recepção e triagem, área administrativa, atendimento de saúde (enfermagem, cuidados odontológicos, nutricionais) e psicossocial, armazenagem e depósito de mercadorias, espaços educacionais, de recreação, comunitários e para animais. A recepção deve contar uma área protegida de $20 \mathrm{~m}^{2}$, próxima à entrada do acampamento. Ainda, os centros médicos devem ser de fácil acesso e bem ventilados, não sendo necessário a permanência de médicos após a triagem inicial em locais com até 200 pessoas. Para espaços de estoque de mercadorias se considera de 75 a $100 \mathrm{~m}^{2}$ para cada 500 pessoas. Áreas educacionais devem ser previstas, sendo que podem ser salas para 40 alunos. Os espaços de recreação devem estar na porção central do acampamento próximo às áreas comunitárias, que devem ser de 15 a $20 \%$ do acampamento. Ademais, deve-se considerar uma área destinada ao abrigo de animais domésticos.

\section{Infraestruturas Básicas}

Devem ser oferecidas infraestruturas como cozinhas, refeitórios, latrinas, lavatórios, chuveiros e áreas de serviço. Ainda, deve-se levar em conta áreas de recepção, processamento e distribuição de alimentos, especialmente voltado à alimentação de crianças e bebês. As cozinhas devem ter área mínima de $15 \mathrm{~m}^{2}$, que atendem até 250 pessoas. O refeitório deve possuir área de $1,5 \mathrm{~m}^{2}$ por pessoa. As áreas de estoque de alimentos devem estar protegidas, bem ventiladas e iluminadas e devem contar com 2 refrigeradores. Em termos de higiene, devem ser oferecidas latrinas, 1 a cada 20 pessoas, lavatórios 1 a cada 10 pessoas, sanitários 1 a cada 25 pessoas e área de serviço 1 tanque de lavar roupa para o intervalo de 40 a 100 pessoas. Os espaços devem ser bem iluminados para uso noturno.

\section{Segurança e Privacidade}

O acampamento deve garantir a segurança das pessoas contra intempéries climáticas e assegurar a privacidade mediante divisões espaciais para os distintos grupos sociais de diferentes idades e gêneros. Deve ser previsto inspeções periódicas para manutenção das atividades no local. Também deve contar com um sistema de prevenção de incêndio. Ainda, deve-se prever uma boa iluminação no acampamento para que se torne seguro em qualquer horário do dia.

\section{Saneamento Básico}

Em termos de saneamento básico, os acampamentos devem prever soluções de esgoto, fornecimento de energia, gerenciamento dos resíduos sólidos, drenagem e abastecimento de água. No local, deve haver coleta de esgoto ou outro tipo de tratamento. Ainda, o acampamento deve contar com gerador de energia ou outras fontes alternativas. A coleta de resíduos sólidos deve ser feita, sendo possível incinerar o lixo na falta desta. O acesso a água pode se dar por superfícies de coleta, poços ou abastecimento por viatura. A estimativa de consumo é de 15 a 20 litros/pessoa/dia (2,5 litros para beber em dias quentes e 2,0 em dias frios).

\begin{tabular}{|c|}
\hline Acesso e Acessibilidade \\
\hline $\begin{array}{l}\text { As ruas devem ser de } 20 \text { a } 25 \% \text { do acampamento, conectan- } \\
\text { do os espaços internos. O acesso aos abrigos individuais deve } \\
\text { ser mediante vias semi-privadas, garantindo a conexão com } \\
\text { as demais estruturas como banheiros, setor de alimentação, } \\
\text { entre outros. Ainda, o acampamento deve contar com rotas } \\
\text { fáceis de acesso e evacuação. Deve-se levar em conta a aces- } \\
\text { sibilidade universal, sendo imprescindível cumprir com as } \\
\text { normas e os procedimentos de aprovação de construções. }\end{array}$ \\
\hline Adequação Cultural \\
\hline $\begin{array}{l}\text { O abrigo deve levar em conta para seu planejamen- } \\
\text { to e administração o contexto sócio-cultural, respei- } \\
\text { tando os padrões culturais e priorizando a utiliza- } \\
\text { ção de materiais e técnicas construtivas locais. }\end{array}$ \\
\hline Meio Ambiente \\
\hline $\begin{array}{l}\text { Os assentamentos devem propiciar um conforto ambiental aos } \\
\text { residentes, garantindo locais bem ventilados e áreas protegidas, } \\
\text { aproveitando a iluminação solar e o vento. Ainda, deve ser evitado } \\
\text { atividades que causem impacto ambiental negativo. Assim, os } \\
\text { acampamentos devem se adaptar às variações climáticas. }\end{array}$ \\
\hline
\end{tabular}

Quadro 2 - Indicadores de estrutura dos abrigos.

Fonte: elaborado pelos autores com base em Carbonari (2021); Sphere Association (2018); SEDEC-RJ (2006).

\section{RESULTADOS PRELIMINARES}

\subsection{Estrutura base de composição do catálogo}

Utilizando como referência os modelos de indicadores abordados nos Quadros 1 e 2, determinou-se uma estrutura base para a catalogação dos acampamentos planejados. Com o intuito de se situar no contexto da criação do abrigo, serão abordados dados como a emergência ocorrida, a data de implantação e a localização. Já caracterizando o acampamento, sistematiza-se o número de pessoas acolhidas, a administração, as infraestruturas e a estrutura do acampamento. Ainda, explora-se os abrigos individuais, indicando o custo e a estrutura. Finalmente, leva-se em consideração a adequação cultural, o impacto sobre o meio ambiente e as principais publicações encontradas sobre o acampamento. A proposição inicial para o catálogo pode ser vista no Quadro 3.

\section{CATÁLOGO DE ACAMPAMENTOS PLANEJADOS}

\begin{tabular}{|l|l|l|}
\hline Emergência (Emergency) & Emergência ocorrida. & Indicar o tipo: conflito social ou desastre natural e sua descrição. \\
\hline Localização (Localization) & Local onde se encontra o acampamento. & $\begin{array}{l}\text { Indicação da localização do acampamento e da distância dos } \\
\text { principais pontos de referência. }\end{array}$ \\
\hline $\begin{array}{l}\text { Data de implantação } \\
\text { (Implantation date) }\end{array}$ & $\begin{array}{l}\text { Data de implantação do acampamento. Caso não esteja mais em vigor, deve-se informar ainda a data de } \\
\text { encerramento. }\end{array}$ \\
\hline $\begin{array}{l}\text { Total de pessoas afetadas } \\
\text { (Total people affected) }\end{array}$ & Número de pessoas acolhidas. \\
\hline $\begin{array}{l}\text { Administração } \\
\text { (Administration) }\end{array}$ & Indica os responsáveis pela administração dos acampamentos. \\
\hline
\end{tabular}




\begin{tabular}{|c|c|c|}
\hline \multirow{4}{*}{$\begin{array}{l}\text { Estrutura do acampa- } \\
\text { mento (Camp structure) }\end{array}$} & Área. & Indicação da área aproximada do acampamento \\
\hline & Expansão. & Indicar se há possibilidades de expansão para o acampamento. \\
\hline & Layout do acampamento. & Mostrar o layout do acampamento. \\
\hline & $\begin{array}{l}\text { Área de recepção e triagem; área admi- } \\
\text { nistrativa; área de armazenagem, depósi- } \\
\text { to de mercadorias; áreas para a recepção } \\
\text { e estoque de itens alimentícios; áreas } \\
\text { para atendimento psicossocial e de saú- } \\
\text { de; espaço educacional e de recreação; } \\
\text { áreas comunitárias; cozinha; refeitório; } \\
\text { área de serviço, entre outras. }\end{array}$ & $\begin{array}{l}\text { Indicar a descrição, quantidade, área, dimensões, sistema cons- } \\
\text { trutivo e a posição no acampamento. }\end{array}$ \\
\hline \multirow{2}{*}{$\begin{array}{l}\text { Serviços básicos do acam- } \\
\text { pamento e acessos } \\
\text { (Camp basic servi- } \\
\text { ces and access) }\end{array}$} & Acesso ao local & Explicar o funcionamento das vias de acesso e das entradas. \\
\hline & $\begin{array}{l}\text { Serviços básicos: esgoto sanitário; ener- } \\
\text { gia; resíduos sólidos; água; drenagem; } \\
\text { latrinas; lavatórios; chuveiros. }\end{array}$ & Indicar as soluções adotadas. \\
\hline Custo (Cust) & \multicolumn{2}{|c|}{ Custo de implantação do acampamento e dos abrigos. } \\
\hline $\begin{array}{l}\text { Estrutura dos abrigos indi- } \\
\text { viduais (Shelter structure) }\end{array}$ & Características. & $\begin{array}{l}\text { Indicar o tipo, a área, as dimensões e a quantidade de unidades } \\
\text { no acampamento. }\end{array}$ \\
\hline \multirow[t]{2}{*}{ Segurança (Security) } & Segurança do acampamento. & $\begin{array}{l}\text { Indicar se o acampamento se localiza em área de risco, descrever } \\
\text { como se dá a segurança no entorno e nas saídas. }\end{array}$ \\
\hline & Segurança dos residentes. & $\begin{array}{l}\text { Indicar como se dá o controle dos moradores e se há a presença } \\
\text { de conflitos. }\end{array}$ \\
\hline $\begin{array}{l}\text { Adaptação cultural } \\
\text { (Cultural adaptation) }\end{array}$ & \multicolumn{2}{|c|}{$\begin{array}{l}\text { Implementação de estratégias para adaptação à cultura local, Projetos de equidade social e desenvolvimen- } \\
\text { to sócio-econômico e Acessibilidade Universal. }\end{array}$} \\
\hline $\begin{array}{l}\text { Meio ambiente e susten- } \\
\text { tabilidade (Environment } \\
\text { and sustainability) }\end{array}$ & \multicolumn{2}{|c|}{$\begin{array}{l}\text { Conforto ambiental oferecido pelo acampamento e pelos abrigos, possíveis interferências ou impactos no } \\
\text { meio ambiente e soluções sustentáveis. }\end{array}$} \\
\hline Publicações (Publications) & \multicolumn{2}{|c|}{ As principais publicações sobre o acampamento, que expressam a relevância do assunto. } \\
\hline
\end{tabular}

Quadro 3 - Catálogo de acampamentos planejados.

Fonte: elaborado pelos autores (2021).

\subsection{Lista de acampamentos encontrados}

Adotou-se como critério de escolha dos acampamentos planejados a serem catalogados os principais eventos que ocorreram nos últimos onze anos, após 2010 sejam desastres ou conflitos, no Brasil e no mundo.

\subsubsection{Acampamentos brasileiros}

No Brasil, utiliza-se de acampamentos planejados para acolher refugiados vindos de outros países. De acordo com a ACNUR-BRASIL (c2021), o país recebe imigrantes da Venezuela, Síria, Angola e Congo. Dentre estes, destacam-se os venezuelanos, cuja principal cidade de entrada é Boa Vista, em Roraima (CARBONARI, 2021). Já em relação a desastres naturais, o Brasil destaca-se pela frequência da ocorrência de inundações (EM-DAT, c2020), além de acidentes envolvendo barragens de mineradoras. Para acoIher os desabrigados, uma das soluções mais utilizadas é a implementação de abrigos em ambientes pré-existentes e fixos como escolas, ginásios e centros comunitários, que permitem o acesso a toda a rede de infraestrutura urbana que o local já possuía (SEDEC-RJ, 2006). Assim, os principais abrigos brasileiros são:
- Acampamento Pintolândia, Tancredo Neves, Jardim Floresta, Nova Canaã, Santa Teresa, Hélio Campos, Latife Salomão, São Vicente e Rondon I em Bela Vista (RO);

- Abrigos instalados para os desabrigados resultante da quebra das barragens em Mariana e em Brumadinho, MG; e,

- Inundações ocorridas na região Serrana do Rio de Janeiro, nas cidades de São José do Rio Preto, Teresópolis, Nova Friburgo, Bom Jardim, Petrópolis, Sumidouro, Areal.

\subsubsection{Acampamentos internacionais}

Em relação aos acampamentos planejados para refugiados de conflitos, se destacam alguns países da Ásia e da África, nos quais ocorrem conflitos armados que causam a dispersão de pessoas para outros países. Se destacam nesse contexto os refugiados da Síria, Afeganistão, Sudão do Sul e Mianmar. Os abrigos selecionados foram:

- Duzce na Turquia,

- Zaatari na Jordânia,

- Azraq na Jordânia,

- Ajuong Thok no Sudão,

- Dadaab em Kenya,

- Bentiu no Sudão do Sul, e 
- Férério em Burkina Faso,

- Dollo Ado na Etiópia,

- Tunaydbah no Sudão.

Os desastres naturais ocorrem mais próximos às divisas de placas tectônicas, pelo movimento destas, como terremotos, maremotos, entre outros. Entre as principais regiões afetadas se encontram os países na costa do pacífico e do oceano Índico. Dessa forma, nos últimos 10 anos foi possível perceber que dentre os principais fenômenos intensos destacaram-se principalmente terremotos, ciclones, tufões e deslizamentos de terra. Assim, os desastres que utilizaram de abrigos são:

- Terremoto no Haiti em 2010,

- Terremoto no Nepal em 2015,

- Tufâo Haiyan (Yolanda) nas Filipinas em 2013 na comunidade de Sungko e na cidade de Tacloban,

- Tsunami no Japão em 2011,

- Terremoto no Equador em 2016 nas províncias de Manabí e Esmeraldas,

- Deslizamento de terra do Peru em 2012, e

- Ciclone Evans na llha de Samoa em 2012,

- Terremoto na Indonésia em 2015.

\subsection{Aplicação da estrutura de catalogação para o caso do acampamento Zaatari}

Para a exemplificação da aplicação do catálogo desenvolvido, utilizou-se o acampamento Zaatari, na Jordânia, baseado-se em UNHCR (2016, 2017, 2019b, 2020, 2021b), UNHABITAT; IFRC (2014), OXFAM International (c2021), Shelter Project (2013-2014), UNICEf (2018a e b) e Alshawawreh (2017).

Emergência (Emergency): Acampamentos criados para acolher refugiados de conflitos na Síria.

Localização (Localization): O acampamento está localizado no norte da Jordânia, nas terras do distrito de Badiah Gharbiyah, Mafraq Governorate, localizado a $75 \mathrm{~km}$ do sul de Amman e a 12 km da fronteira com a Síria (Figura 2).

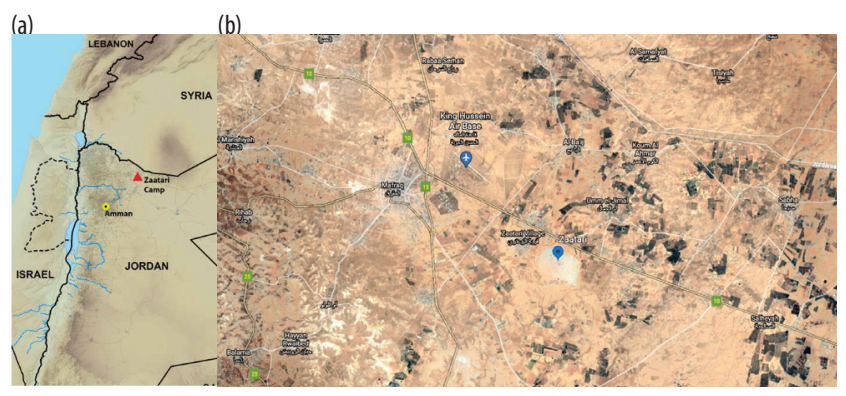

Figura 2 - (a) Mapa esquemático da localização, (b) Localização do acampamento. Fonte: UNHCR (2017); adaptado do Google Earth (2021).

Data de implantação (Implantation date): julho de 2012. Em atividade.
Total de pessoas afetadas (Total people affected): 78,685 refugiados (2021).

Administração (Administration): A administração no acampamento é feita pela Diretoria de Assuntos de Refugiados da Síria (SRAD) e pela UNHCR. Este último assume a coordenação do acampamento, ou seja, a elaboração da estratégia geral adotada na coordenação operacional e nos grupos de trabalho dos diversos setores. Ainda, é encarregado da em proteção, saúde, abrigo e planejamento do local, segurança e mobilização comunitária. Além dessas instituições, o acampamento conta com a colaboração de diversas organizações internacionais, entre elas se encontram: Fundo das Nações Unidas para a Infância (UNICEF), Conselho Norueguês de Refugiados (NRC), Comitê Internacional da Cruz Vermelha (ICRC), Agência de Cooperação Técnica e Desenvolvimento (ACTED), Mercy Corps, Comitê Internacional de Resgate (ICR), Corpo Médico Internacional (IMC), Sociedade de ajuda humanitária da Jordânia (JHAS), OXFAM, entre outros.

Estrutura do acampamento (Camp structure): $O$ acampamento conta com $5,3 \mathrm{Km}^{2}$. Apresenta 12 distritos, separados por vias de circulação principais. Cada distrito se divide em parcelas numeradas de terra, com fronteiras definidas denominadas de blocos, onde se localizam os abrigos individuais (figura 3).

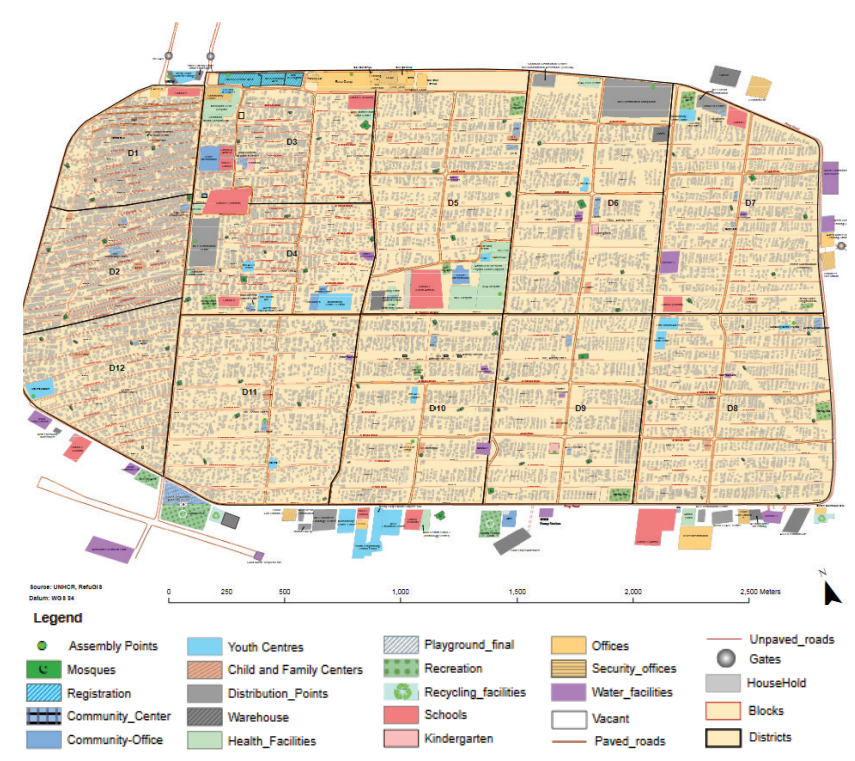

Figura 3 - Imagem do acampamento. Fonte: adaptado de UNHCR (2017).

Os abrigos individuais deveriam estar posicionados em filas, mas os residentes optaram por se posicionar em formato de $U$, permitindo que as famílias vivessem mais próximas. Assim, o mapa do acampamento se assemelha a um labirinto (Figura 4). 


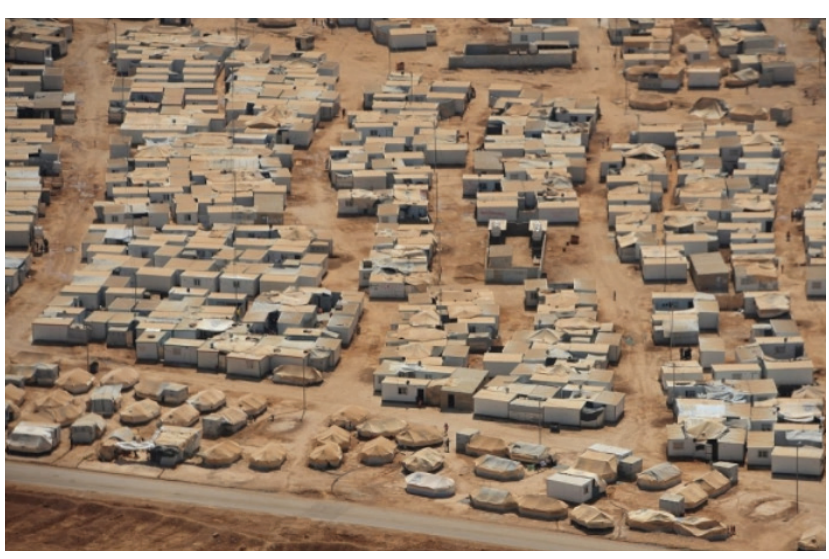

Figura 4 - Vista interna lotes.

Fonte: Google Maps (2021).

Em termos de estruturas presentes no acampamento, é possível observar que há espaços administrativos destinados às organizações e administradores do acampamento como a UNICEF, Mercy Corps, Defesa Civil, UNHCR,
SRAD, ICRC, além da base do acampamento. Já em termos de recepção, triagem, armazenagem e depósito de mercadorias, há espaços destinados à distribuição de itens necessários para os refugiados. Dentre eles se encontram no nordeste do acampamento o Centro de distribuição comum para assistência humanitária (CDCHA), Centro de distribuição da NRC e WFP Bread Distribution.

Dentre as estruturas que visam atender a comunidade, é possível observar escolas, creches e escolas dirigidas pela UNICEF. Ainda há diversos espaços de recreação como parques infantis e campos de futebol. As áreas comunitárias envolvem centros comunitários para adultos, jovens, crianças e familiares. Nestes, a população pode realizar cursos, atividades recreativas e esportivas, jogos infantis, desenvolvimento de habilidades, entre outros. Para tratamento de saúde é possível observar hospitais e centros médicos que atendem desde crianças até idosos. Além disso, outros serviços são oferecidos: mesquitas, supermercados, lojas de roupa e shopping center e lojas de eletrônicos (Figura 5). (a)

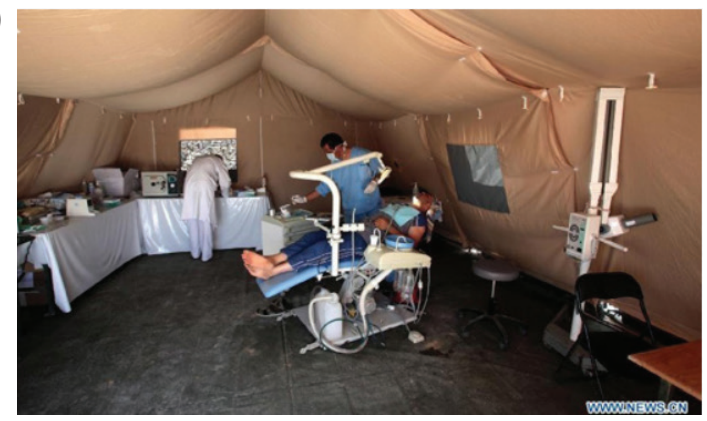

(c)

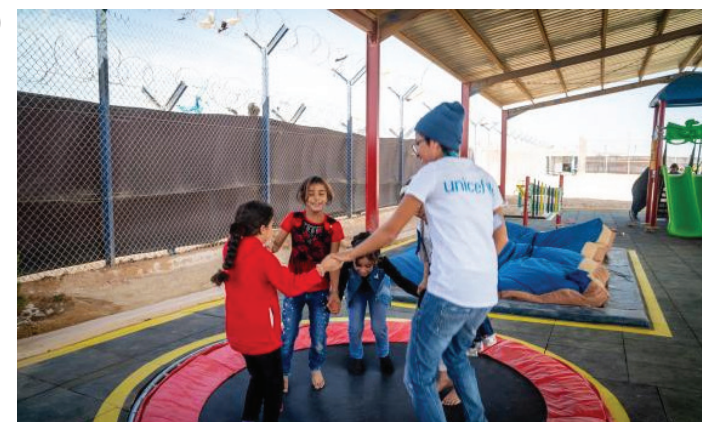

(e)

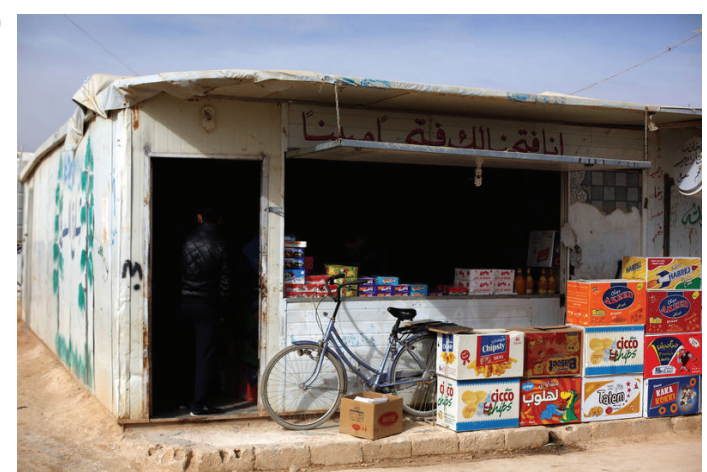

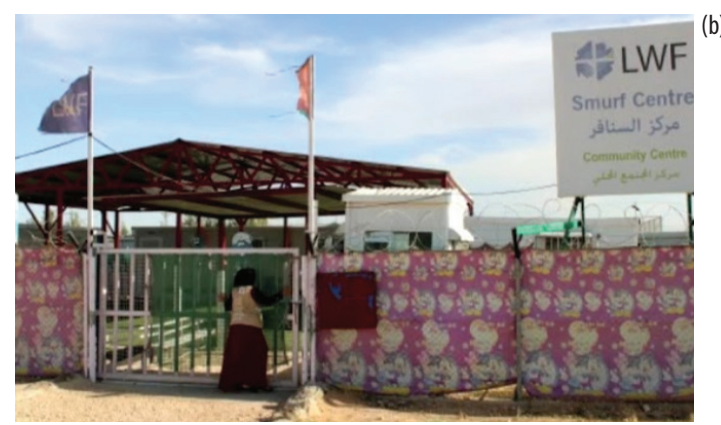
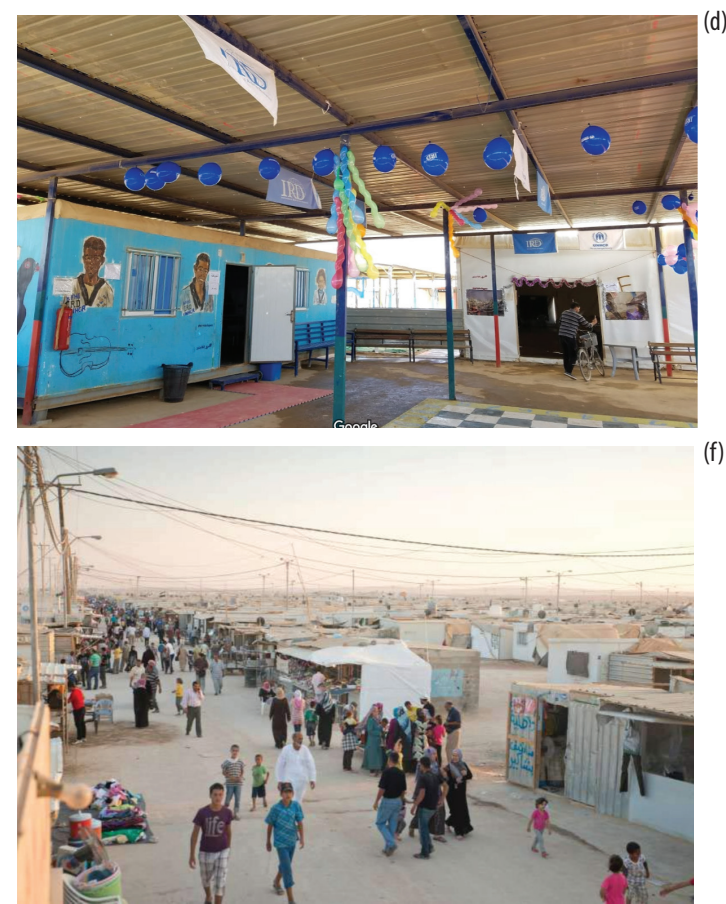

Figura 5 - (a) Centro Médico; (b) Centro comunitário; (c) (d) Escola; (e) Supermercado; (f) Comércio. Fontes respectivamente: Global Times (2012); Google Maps (2021); UNICEF, b (2018); Google Maps (2021); Investing.com (2016); Google Maps (2021). 
Alguns serviços como cozinhas, refeitórios, áreas de serviço, banheiros, entre outros, inicialmente eram compartilhados. No entanto com o aumento do vandalismo e do número de moradores no acampamento estas estruturas passaram a ser privativas, sendo encontradas nos abrigos individuais (figura 6).

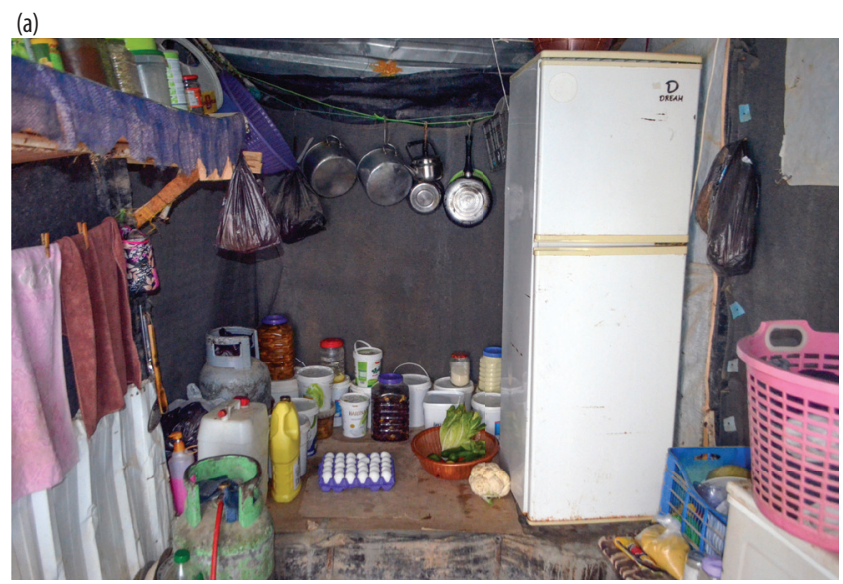

(b)

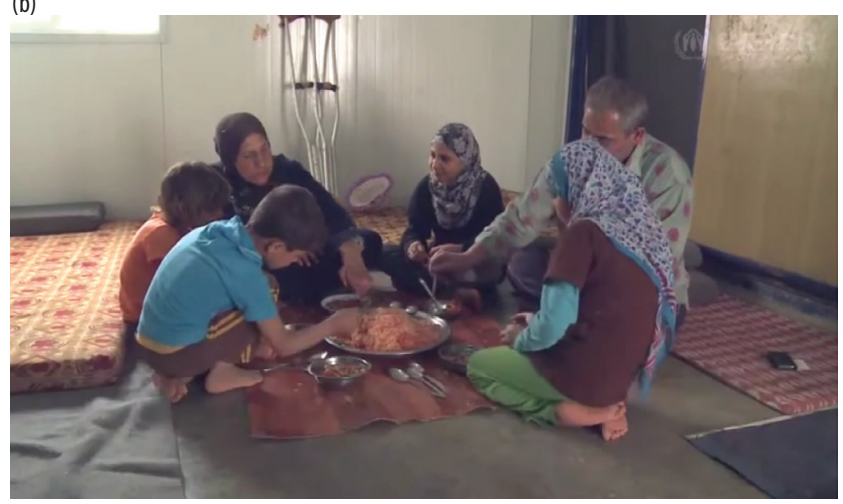

Figura 6 - (a) Cozinha em um abrigo individual; (b) Refeição no abrigo individual. Fonte: Batah, 2018; UNHCR, 2021c.

\section{Serviços básicos do acampamento e acessos (Camp} basic services and access): Dentre a infraestrutura básica, se destaca o acesso a água e energia elétrica. No abrigo, eram utilizados caminhões-pipa, entregando água a cada três dias. Os moradores recebem 35 litros por dia. $O$ sistema de esgoto apresentava três soluções: armazenamento em fossas ou tanques, o escoamento superficial mediante a construção de valas no solo e a ligação à rede ou ao bloco WASH. Em 2018, propôs-se a construção da rede de água e de coleta de águas residuais. Ainda, em 2020, há no acampamento três poços internos e uma estação de tratamento de esgoto. Em termos de energia elétrica, em 2012, a rede elétrica foi estabelecida para o uso no acampamento, mas os próprios refugiados realizaram as instalações nas unidades. Assim, em 2015 o sistema foi refeito, pois o antigo era perigoso.
Custo (Cust): 2,94 US\$ por barraca, incluindo coleta do acampamento, avaliação da barraca, materiais de reparo, remendos e reembalagem.

Estrutura dos abrigos individuais (Shelter structure): Em um primeiro momento, eram distribuídas tendas às famílias pela UNHCR. No entanto, devido ao clima de deserto do local, utilizou-se novas soluções de abrigos, substituindo as tendas. Adotou-se construções com containers e em alvenaria. Percebe-se a presença de materiais como tijolos cerâmicos, blocos de concreto, estruturas em concreto armado (pilares e vigas) e chapas/placas de diversos materiais (madeira, metais e lonas). Os containers standard 20-foot (6 metros), apresentam painéis sanduíche isolados com poliuretano nas paredes e nos telhados (figura 7).

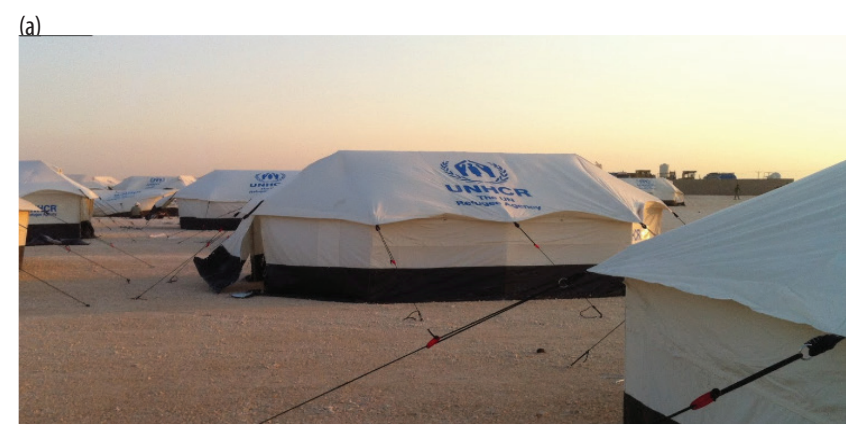

(b)

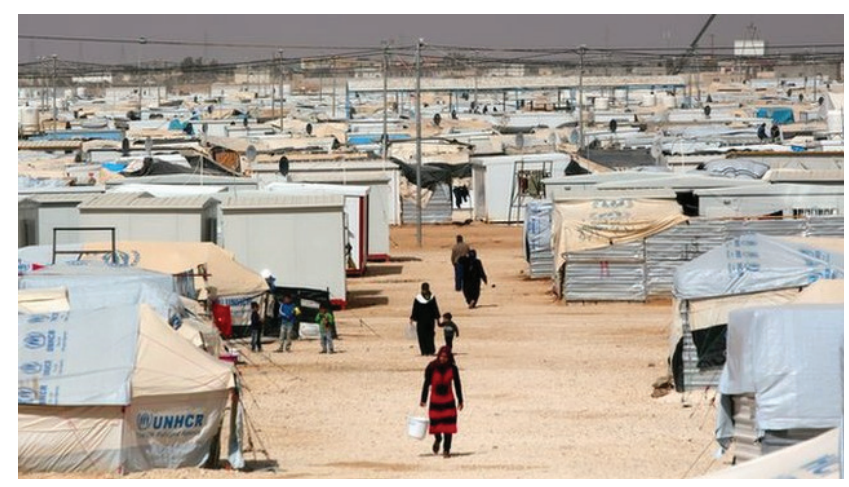

Figura 7 - (a) Tendas Acnur; (b) abrigos individuais. Fonte: Google Maps (2021); BBC News (2016).

Segurança (Security): O acampamento está localizado em uma área praticamente plana, com pouco desnível, mas com locais que são suscetíveis a inundações, ocorridas devido às fortes chuvas. Os distritos 1 e 2 são os mais seguros. Em termos de acesso, no abrigo é possível perceber 4 entradas, que nem sempre apresentam um bom controle, sendo já relatados casos de contrabando de produtos como barracas, colchões, gás, entre outros, originando um mercado negro. Ainda, percebeu-se conflitos internos e com a comunidade local. Internamente, houveram conflitos entre os líderes dos moradores, 
denominados de Street Leaders, e os administradores do acampamento, sendo que em 2013 ocorreram confrontos violentos com a polícia. Já em relação ao meio externo, com a vinda dos refugiados, aumentou a população e o custo de vida nas aldeias e vilas vizinhas, gerando manifestações que cobram o aumento dos serviços públicos. Ainda, a UNHCR estabeleceu uma rede de proteção comunitária, composta por por 90 voluntários, sendo 39 mulheres e 51 homens, que pretende fortalecer os mecanismos de prevenção e resposta de incidentes, assim como identificar as preocupações da comunidade.

Adaptação cultural (Cultural adaptation): Os moradores realizaram diversas adaptações nos abrigos. Por exemplo, infraestruturas como cozinhas e banheiros eram comunitárias, no entanto, devido a questões de privacidade, alguns moradores, expandiram seus abrigos para alojar estes serviços. Há também redes de encontros comunitários que garantem uma comunicação entre a comunidade e a população refugiada, com o intuito de garantir o envolvimento dos refugiados nas decisões, definição de necessidades e prioridades, entre outros (figura 8).

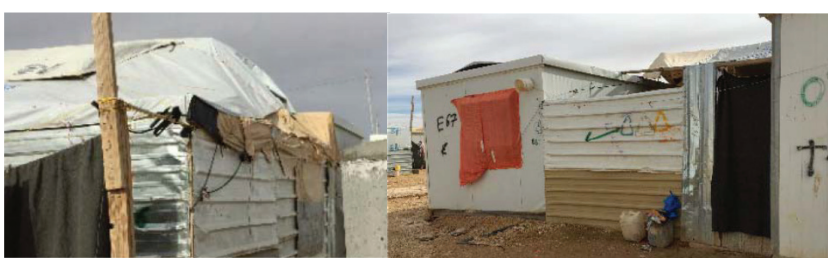

Figura 8 - Áreas estendidas e modificadas. Fonte: Alshawawreh (2017).

Meio ambiente e sustentabilidade (Environment and sustainability): Em termos de impactos sobre o meio ambiente, realizou-se um projeto de reciclagem das barracas que não estavam mais sendo utilizadas. Assim, à medida que os novos abrigos eram implantados, os materiais das barracas eram separados em três categorias: as que poderiam ser utilizadas, as que estavam danificadas e as que poderiam ser reparadas. Com o material se realizaram alguns objetos de uso doméstico. Ainda, em termos de sustentabilidade, a água que é tratada no acampamento é utilizada em fazendas locais para a agricultura (figura 9).

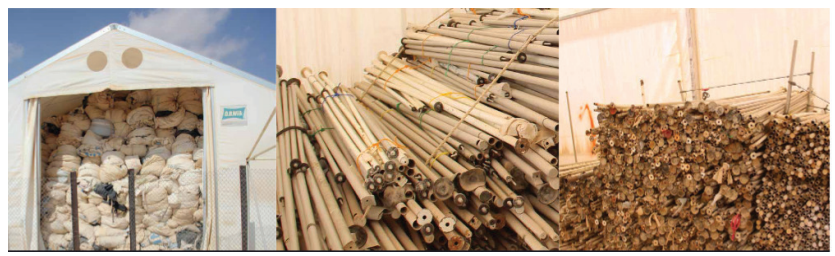

Figura 9 - Estoque das tendas para reciclagem. Fonte:UN-HABITAT; IFRC (2014).
Publicações (Publications): o catálogo deverá apresentar o link para as publicações. Essas publicações mostram as informações sobre o acampamento, e assim explicitam a importância de conhecer esse acampamento.

- ALSHAWAWREH, Lara; SMITH Sean R.;Wood John B. Assessing the Sheltering Response in the Middle East: Studying Syrian Camps in Jordan. International Journal of Social, Behavioral, Educational, Economic, Business And Industrial Engineering, v. 11, n. 8, p. 1751-1757, ago. 2017. Disponível em: https://www.napier.ac.uk/ /media/worktribe/output-965481/assessing-the-sheltering-response-in-the-middle-east-studying-syrian-camps-in-jordan-1. pdf. Acesso em: 05 jan. 2021.

- SHELTER PROJECTS 2013-2014. Disponível em: http:// shelterprojects.org/shelterprojects2013-2014/SP13-14_ A12-Jordan-2014.pd Acesso em: 08 jan. 2021.

- OXFAN INTERNATIONAL. Zaatari Refugee Camp. c2021. Disponível em: https://www.oxfam.org/en/life-zaatari-largest-syrian-refugee-camp-world. Acesso em: 10 jan. 2021.

- UNHCR. Refugees Situation: Impacts of electricity - Participatory impact assessment of electricity access in Zaatari and Azraq camps in UNHCR Jordan. Fev 2019. Disponível em: https://data2.unhcr.org/en/documents/ details/67947. Acesso em: 15 jan 2021.

- UNHCR. Refugees Situation: Syria Regional Refugee Response. Fev 2020. Operational Portal. Disponível em: https://data2.unhcr.org/en/documents/details/73845. Acesso: 08 jan. 2021.

- UNHCR Refugees Situation: Syria Regional Refugee Response. Fev 2021. Operational Portal. Disponível em: https://data2.unhcr.org/en/situations/syria/location/53. Acesso: 08 jan. 2021.

- UNICEF. Environment friendly and cost efficient water and sanitation network in Za'atari Camp. Maio, 2018. a. Disponível em: https://www.unicef.org/jordan/press-releases/environment-friendly-and-cost-efficient-water-and-sanitation-network-zaatari-camp. Acesso: 18 jan 2021.

- UNICEF. Inclusive playground opens in Za'atari refugee camp. Dez 2018. b. Disponível em: https://www.unicef.org/jordan/stories/inclusive-playground-opens-zaatari-refugee-camp. Acesso em: 10 jan. 2021.

- UN-HABITAT; IFRC. Jordan - 2014 - Syria conflict, 2014. Disponível em:http://shelterprojects.org/shelterprojects2013-2014/SP13-14_A12-Jordan-2014.pdf. Acesso em: 03 jan.2021 


\subsection{Futura Plataforma Infrashelter e Portal Virtuhab}

A Plataforma Online Infrashelter tem por objetivo a disponibilização das informações obtidas dos acampamentos selecionados. É o resultado final de uma pesquisa que irá durar em torno de três anos, montada com colaboração internacional. O compartilhamento de dados se dará em base ao formato do catálogo desenvolvido. Portanto, nesta primeira etapa não será desenvolvida, ainda assim, sugere-se como referências para a plataforma alguns sites: http://shelterprojects.org; http://recoveryplatform. org; http://data2.unhcr.org; entre outros. Já para a criação poderá se fazer uso de recursos de criação de sites como Wordpress, Google Forms e Wix.

Inicialmente, os catálogos serão disponibilizados no portal Virtuhab (https://portalvirtuhab.paginas.ufsc.br/). Neste, devem ser dispostos links, nos quais ao clicar será possível acessar os catálogos no formato PDF. Os links serão ordenados em dois principais tópicos: desastres naturais (ciclones, terremotos, incêndios, inundações, deslizamento de terra, furacões, tsunami, tufões, erupções vulcânicas) ou conflitos. Ainda, como subtópicos, se encontram a localização geográfica da emergência, divididos em continentes e países. Os catálogos serão nomeados com o nome do acampamento ou a emergência, o ano de ocorrência, e a cidade (figura 10).

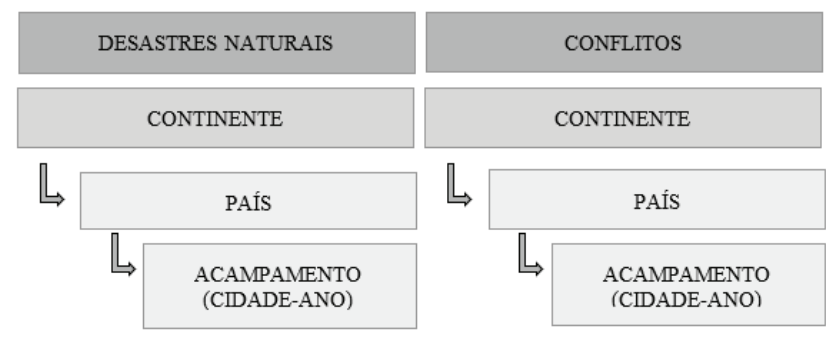

Figura 10 - Estrutura de classificação dos acampamentos no Portal Virtuhab. Fonte: elaborado pelos autores (2021).

\section{CONSIDERAÇÕES FINAIS}

Este artigo retratou a proposta de um sistema de catalogação de estruturas de ajuda humanitária para o acolhimento de vítimas de desastres naturais ou conflitos sociais, mais especificamente de acampamentos planejados. Assim, baseado em indicadores pré-estabelecidos por diversos autores, em especial Carbonari (2021), realizou-se a proposição inicial do catálogo. Ainda, elaborou-se uma relação dos acampamentos que serão catalogados, utilizados para abrigar a população vítima de emergências e conflitos entre 2010 e 2021. Além disso, mostrou-se a maneira que serão disponibilizados, em um princípio no Portal Virtuhab (https://portalvirtuhab.paginas.ufsc. br/) e posteriormente na Plataforma Infrashelter. Dessa maneira, contribui-se para divulgar conhecimentos relacionados ao assunto em questão, de uma forma prática e organizada que normalmente encontram-se dispersos nas bases de dados. Ademais, demonstra-se as diversas possibilidades de soluções de abrigos e acampamentos já adotados, levando em conta as características de cada situação. Assim, tornam-se referências que podem ser consultadas para elaboração de novos acampamentos.

\section{REFERÊNCIAS}

ACNUR-BRASIL. ACNUR. c2021. Disponível em: https:// www.acnur.org/portugues/. Acesso em: 06 jan. 2021.

ALCÁNTARA-AYALA, Irasema. Geomorphology, natural hazards, vulnerability and prevention of natural disasters in developing countries. Geomorphology, Cambridge, v. 47, n. 2-4, p. 107-124, out. 2002.

ALSHAWAWREH, Lara; POMPONI, Francesco; D'AMICO, Bernardino; SNADDON, Susan; GUTHRIE, Peter. Qualifying the Sustainability of Novel Designs and Existing Solutions for Post-Disaster and Post-Conflict Sheltering. Sustainability, v. 12, n. 3, p. 890, jan 2020. ALSHAWAWREH, Lara; SMITH Sean R.;Wood John B. Assessing the Sheltering Response in the Middle East: Studying Syrian Camps in Jordan. International Journal of Social, Behavioral, Educational, Economic, Business And Industrial Engineering, v. 11, n. 8, p. 1751-1757, ago. 2017. Disponível em: https://www.napier.ac.uk/ /media/worktribe/output-965481/assessing-the-sheltering-response-in-the-middle-east-studying-syrian-camps-in-jordan- 1 . pdf. Acesso em: 05 jan 2021.

BBC NEWS, Syria conflict: Jordan's Zaatari refugee camp from the air. 2016. Disponível em: https:// www.bbc.com/news/av/world-middle-east-35492705. Acesso em: 15 nov. 2020.

CARBONARI, L. T.; LIBRELOTTO, L. I. Indicadores e diretrizes para a seleção e projeto de abrigos temporários móveis pós-desastres naturais. In: ENCONTRO DE SUSTENTABILIDADE EM PROJETO, 6. 2018, Florianópolis. Anais do ENSUS. Florianópolis: UFSC, 2018. p. 1465-1474.

CARBONARI, Luana Toralles. Modelo multicritério de decisão para o projeto de acampamentos temporários planejados voltados a cenários de desastre. 2020. 409 f. Tese (Doutorado) - Curso de Arquitetura e Urbanismo, Universidade Federal de Santa Catarina, Florianópolis, 2021. 
CORSELLIS, T.; VITALE, A (Coords.). Transitional settlement: displaced populations. University of Cambridge: Oxfam. 2005. 239 p.

DE CASTRO, Antônio Luiz Coimbra. Glossário de defesa civil estudos de riscos e medicina de desastres.Segunda edição: revisada e ampliada. Brasília: Ministério da Integração Nacional, 2009.

EM-DAT. The EM-DAT Atlas. c2020. Disponível em: https://www.emdat.be/emdat_atlas/. Acesso em: 18 jan. 2021.

GLOBAL TIMES. Syrian refugees at Zaatari camp in Jordan. 2012. Disponível em: https://www.globaltimes.cn/content/726418.shtml. Acesso em: 22 jan. 2021. INVESTING.COM. At Zaatari camp supermarket, Syrian refugees shop with blink of an eye. 2016. Disponível em: https://www.investing.com/news/ world -news/at-zaatari-camp-supermarket,-syrian-refugees-shop-with-blink-of-an-eye-444042. Acesso em: 7 jan. 2021.

LEMES, Giovanna Loíse da Cruz; REZENDE, Alex Nogueira. Habitações emergenciais em situações de desastres ambientais. Arquitextos, São Paulo, n. 232.02, set. 2019. Disponível em: https://vitruvius.com. $\mathrm{br} / \mathrm{revistas} / \mathrm{read} /$ arquitextos/20.232/7520 . Acesso em: 10 dez. 2020.

BATAH, Mohadmmad. A single mother supports her family in Zaatari camp. Medium.com. 2018. Disponível em: https://medium.com/world-food-programme-insight/a-syrian-refugee-story-d75e6a32e28f. Acesso em: 15 jun. 2021.

NAPPI, M. M. L.; SOUZA, J. C. Disaster management: hierarchical structuring criteria for selection and location of temporary shelters. Natural Hazards, v. 75, n. 3, p. 2421-2436, 2014.

OXFAN INTERNATIONAL. Zaatari Refugee Camp. c2021. Disponível em: https://www.oxfam.org/en/life-zaatari-largest-syrian-refugee-camp-world. Acesso em: 10 jan. 2021.

QUARANTELLI, Enrico Louis. Patterns of sheltering and housing in American disasters. 1991.

SECRETARIA DE ESTADO DA DEFESA CIVIL DO RIO DE JANEIRO. Administração para Abrigos Temporários. Rio de Janeiro: SEDEC/RJ, 2006. 244 p.

SPHERE ASSOCIATION. The Sphere Handbook: Humanitarian Charter and Minimum Standards in Humanitarian Response. 4.ed. Genevra. 2018

SHELTER CENTRE. Shelter After Disaster: Strategies for transitional settlement and reconstruction, p. 194, 2010.
SHELTER PROJECTS 2013-2014. Disponível em: http:// shelterprojects.org/shelter projects2013-2014/SP13 14_A12-Jordan-2014.pd Acesso em: 08 jan. 2021. TOMINAGA, Lídia Keiko; SANTORO, Jair; AMARAL, Rosangela do. Desastres Naturais: conhecer para prevenir. São Paulo: Instituto Geológico, 2009. UN-HABITAT; IFRC. Jordan - 2014 - Syria conflict, 2014. Disponível em:http://shelterprojects.org/shelterprojects2013-2014/SP13-14_A12-Jordan-2014.pdf. Acesso em: 03 jan.2021.

UNHCR. SHELTER DESIGN CATALOGUE. Switzerland, 2016, 68 p. Disponível em: https://cms. emergency.unhcr.org/documents/11982/57181/ Shelter+Design+Catalogue+January+2016/ a891fdb2-4ef9-42d9-bf0f-c12002b3652e.

UNHCR. Emergency Handbook: Emergency Shelter Standard. p. 1-11, 2019. a. Disponível em: https://emergency.unhcr.org/entry/36774/ emergency-shelter-standard.

UNHCR. Emergency Handbook: Spontaneous settlement strategy guidance. p. 1-6, 2021. a. Disponível em: https://emergency.unhcr.org/entry /33275/spontaneous-settlement-strategy-guidance.

UNHCR. Food at Za'atari Camp. c2021. c. Disponível em: https://www.unhcr.org/7steps/en/food/. Acesso em: 07 jun. 2021.

UNHCR. Refugees Situation: Impacts of electricity - Participatory impact assessment of electricity access in Zaatari and Azraq camps in UNHCR Jordan. Fev 2019. b. Disponível em: https://data2.unhcr.org/ en/documents/details/67947. Acesso em: 15 jan 2021.

UNHCR. Refugees Situation: Syria Regional Refugee Response. Fev 2020. Operational Portal. Disponível em: https://data2.unhcr.org/en/documents/details/73845. Acesso: 08 jan. 2021.

UNHCR Refugees Situation: Syria Regional Refugee Response. Fev 2021. b. Operational Portal. Disponível em: https://data2.unhcr.org/en/situations/syria/location/53. Acesso: 08 jan. 2021.

UNHCR. Zaatari Camp's Facilities Map, abr 2017. Disponível em: https://data2.unhcr.org/en/documents/details/55994. Acesso em: 08/02/2021.

UNICEF. Environment friendly and cost efficient water and sanitation network in Za'atari Camp. Maio, 2018. a. Disponível em: https://www.unicef. org/jordan/press-releases/environment-friendly-and-cost-efficient-water-and-sanitation-network-zaatari-camp. Acesso: 18 jan 2021.

UNICEF. Inclusive playground opens in Za'atari 
refugee camp. b. Dez 2018. Disponível em: https:// www.unicef.org/jordan/stories/inclusive-playground-opens- zaatari-refugee-camp. Acesso em: 10 jan. 2021.

\section{AUTORES}

ORCID: 0000-0002-8330-5277

THAIS NOLIO SANTA CRUZ | Universidade Federal de Santa Catarina | Arquitetura e Urbanismo | Florianópolis, SC Brasil | Correspondência para: Rua Luiz Oscar de Carvalho, 75 bloco A5 apto 31 - Trindade, Florianópolis - SC, 88036400|tscn.33@gmail.com

ORCID: https://orcid.org/0000-0002-3250-7813

LISIANE ILHA LIBRELOTTO, Dra. | Universidade Federal de Santa Catarina - UFSC | Pos-ARQ - Virtuhab| Florianópolis, SC. Brasil | Correspondência para: Campus Universitário Reitor João David Ferreira Lima, s/nº Trindade - Florianópolis SC CEP: 88040-900 | e-mail: pcferroli@gmail.com

ORCID: 0000-0003-2132-3389

LUANA TORALLES CARBONARI, Dra. | Londrina, PR - Brasil | Correspondência para: Rua Jerusalém 99 bloco 3 apto 302, Cep: 86050-520, Londrina - PR| E-maill: luanatcarbonari@gmail.com

ORCID: 0000-0002-7308-9646

NADIELI DE ARAUJO | Universidade Federal de Santa Catarina | Arquitetura e Urbanismo | Florianópolis, SC - Brasil | Correspondência para: Rua Estoril, Q. 43, L.11 - Forquilhas, São José - SC, 88107-413 | E-mail: araujonadieli@gmail.

\section{COMO CITAR ESTE ARTIGO}

SANTA CRUZ, Thais Nolio; LIBRELOTTO, Lisiane Ilha; CARBONARI, Luana Toralles; ARAUJO, Nadieli de. Catalogação E Sistematização De Acampamentos Planejados - Futura Plataforma Infrashelter. MIX Sustentável, [S.I.], v. 7, n. 4, p. 91-104, set. 2021. ISSN 24473073. Disponível em:<http://www.nexos. ufsc.br/index.php/mixsustentavel>. Acesso em: dia mês. ano. doi:https://doi.org/10.29183/2447-3073. MIX2021.v7.n4.91-104.

DATA DE ENVIO: 30/06/2021

DATA DE ACEITE: 02/07/2021 
